OPEN ACCESS

Edited by:

Andrew M. H. Siu,

Hong Kong Polytechnic

University, China

Reviewed by:

Sujita Kumar Kar,

King George's Medical

University, India

Elizabeth Lauren Budd,

University of Oregon, United States

*Correspondence: Amy A. Eyler

aeyler@wustl.edu

Specialty section: This article was submitted to

Children and Health,

a section of the journal

Frontiers in Public Health

Received: 02 December 2020 Accepted: 11 May 2021

Published: 07 June 2021

Citation:

Eyler AA, Schmidt L, Kepper M,

Mazzucca S, Gillbert A and Beck A

(2021) Parent Perceptions of Changes

in Child Physical Activity During

COVID-19 Stay-At-Home Orders.

Front. Public Health 9:637151.

doi: 10.3389/fpubh.2021.637151

\section{Parent Perceptions of Changes in Child Physical Activity During COVID-19 Stay-At-Home Orders}

\author{
Amy A. Eyler*, Laurel Schmidt, Maura Kepper, Stephanie Mazzucca, Amanda Gilbert and \\ Alan Beck
}

Prevention Research Center in St. Louis, Brown School, Washington University in St. Louis, St. Louis, MO, United States

Purpose: The purpose of this study was to explore parent perceptions of changes in child physical activity during COVID-19 stay-at-home orders.

Design: A cross-sectional study.

Setting: The research team used social media, relevant organizations, and neighborhood groups to distribute the survey link in May and June of 2020.

Subjects: A convenience sample of parents of children aged 5-12.

Measures: Survey to assess parental perceptions of changes in children's physical activity before and during stay-at-home orders, and environmental and social barriers to physical activity.

Analysis: Results were analyzed using descriptive statistics, bivariate comparisons, and multinomial-logistic regression models with covariates of environmental factors, social factors, and frequency of factors as barriers on association with perceived physical activity change.

Results: Data from 245 parents were analyzed. A majority (63.7\%) of parents reported a decrease in children's physical activity during stay-at-home orders. More parents indicated social barriers (e.g., lack of access to playmates) than environmental barriers (e.g., lack of access to neighborhood play spaces) to children's physical activity. In multivariate analyses, the odds of parents reporting decreased physical activity was greater for those reporting lack of playmates $(\mathrm{OR}=4.72 ; 95 \% \mathrm{Cl}: 1.99-11.17)$ and lack of adult supervision ( $\mathrm{OR}=11.82 ; 95 \% \mathrm{Cl}$ : 2.48-56.28) as barriers. No environmental barriers were significantly associated with decreased children's physical activity.

Conclusion: The unique aspects of the COVID-19 pandemic provide a natural experiment for developing social and environmental strategies to improve children's overall physical activity. Assessing parental perceptions is a way to inform these future efforts.

Keywords: children, physical activity, environment, barriers, parenting, social, COVID-19 


\section{INTRODUCTION}

Regular participation in physical activity is consistently associated with many physical and mental health benefits in children $(1,2)$, and there is evidence to support sustainability of these benefits into adulthood (3-5). Despite this evidence, increasing the prevalence of physical activity remains a public health challenge. The majority of children in the United States do not meet the current recommendation that children and youth should achieve at least $60 \mathrm{~min}$ of moderate-to-vigorous intensity physical activity each day $(2,6)$. Rates of physical activity among children and adolescents also vary by age and gender. There are significant decreases in physical activity with increasing age, especially for girls (7-11), with more age-related differences in elementary school than upper grade levels (10).

Restrictions due to the COVID-19 pandemic have added unique challenges to promoting physical activity in children. In an effort to prevent widespread infection of the virus, 42 states and territories issued mandatory stay-at-home orders from March 1 through May 31, 2020 (12). Places where people maintain close physical contact with one another (e.g., schools) were required to close. Since schools are a primary resource for youth activity (13), mandated closures likely impacted physical activity. Physical education and after-school sports programs were halted or limited to virtual options during this time. Opportunities for active commuting to school and recess play were also eliminated by COVID-19 stay-at-home orders. Other extra-curricular, community-based opportunities for physical activity (e.g., dance lessons, sports leagues) were halted.

Outdoor spaces such as parks and playgrounds were also closed during stay-at-home orders. Without access to these outdoor environments, children lost another important resource for physical activity (14). Lack of access to outdoor places to play may have an additional negative impact. For example there is evidence of mental health benefits of outdoor physical activity, particularly related to reduced depression and anxiety (15-17). The absence of outdoor physical activity opportunities coupled with the stressors of the pandemic may contribute to an even greater strain on mental health. Early findings report that maintaining physical activity, especially outdoors, may promote better mental and general health during periods of confinement (18-21).

Stay-at-home orders impacted families in various ways, including adding stress of employment changes as well as financial and physical health implications of the pandemic (22, 23). Many parents and caregivers had to deal with the absence of childcare and the additional task of coordinating children's online schooling. Some parents had to also juggle their own work-athome responsibilities. This may have been especially challenging for families with younger, less independent children, resulting in modifications to usual parenting practices. For example, parents may have allowed more screen time for entertainment to accommodate inability for supervision due to work-at-home responsibilities (24).

Another way stay-at-home orders may have impacted physical activity of children is related to a change in social engagement. The pandemic created an absence of in-person social interaction with friends or extended family members. The transition from actively engaging with friends and peers (e.g., bike riding or playing outside) to socializing online likely exacerbates the negative impact of the absence of other physical activity opportunities.

The COVID-19 pandemic and subsequent stay-at-home orders created unique social and environmental situations which could impact healthy behaviors. The aims of this survey were to (1) explore parent perceptions of changes in children's physical activity during stay-at-home orders; and (2) identify social and environmental factors associated with these changes. The results from this exploratory survey can inform broader assessments to track trends over time and contribute to the development of recommendations to enhance supports for physical activity.

\section{METHODS}

\section{Study Design}

The research team collected cross-sectional data via an anonymous online survey. This study was approved by the Washington University in St. Louis Institutional Review Board.

\section{Sample}

Participants were recruited through convenience sampling on social media (Facebook, Twitter, and MyFitnessPal). Some platforms were geared to a broad, national audience, and others were more local. For example, survey recruitment posts were made to national research center accounts and various St. Louis neighborhood Facebook groups and advocacy groups targeted toward school age children. Sharing of the recruitment message and survey link was also encouraged. To be eligible for the study, participants had to be parents or caregivers of a child or children aged 5-12. Recruitment messages were systematically posted between May 26 and June 26, 2020, with frequencies and days of the week varying by social media platform.

\section{Measures}

The time period of interest for the survey was March through May 2020, during state implementation of stay-at-home orders when schools and worksites were closed, and residents were asked to eliminate non-essential outings. Parents were asked to report perceptions of how their child's physical activity changed during the stay-at-home orders. The survey included questions from an existing scale of child physical activity practices (25) in addition to new questions specific to COVID-19 stay-athome orders. See Appendix 1. The outcome variable of interest was change in child physical activity. Participants were asked "Overall, during the COVID-19 stay-at-home orders, do you feel your child's physical activity: decreased, stayed the same, or increased?" Child age and gender were also assessed. Influence of social environmental factors related to physical activity assessed in the survey were access to playmates, parent schedules, availability of adult supervision, parent interest in physical activity, support from other adults, and family support for physical activity. Influence of the physical environment assessed in the survey included access to neighborhood places for physical activity, size and layout of indoor spaces, size and layout of 
yard, and neighborhood safety. In order to identify perceived barriers to their child's physical activity, participants were asked to identify listed social and physical environmental factors which limited their children's physical activity. The survey was tested $(N=5)$ with parents of children in the required age range and no substantive changes were made. A link to the survey was included in recruitment messages and distributed. Parents with more than one child in the eligible age range were instructed to answer the survey based on a single child chosen at their discretion.

\section{Analysis}

Data were analyzed with IBM SPSS 26.0 software. Significance was set at $p<0.05$ for analyses. Of 471 survey responses, 214 were eliminated from analysis as they lacked information on either the dependent or independent variables. An additional eight cases were excluded from analysis as the children were either too young or too old for the scope of the study and four were omitted as influential outliers based on a combination of Cook's Distances in excess of 1.5 , dfbetas in excess of 2 , and standardized residuals in excess of 3 . The final analytic sample included 245 parents.

Data were explored using descriptive statistics, frequency tables, and bivariate analyses. Correlations were assessed using Pearson's chi-square and one-way ANOVA tests.

Two multinomial logistic regressions were conducted to assess association of factors reported as barriers with change to children's physical activity. Dependent variables for the regression models were (1) decreased physical activity compared to increased or remained the same; and (2) increased physical activity compared to decreased or remained the same. The first regression included parent perception of social factors as barriers related to physical activity (availability of adult supervision, parent interest, parent schedule, support from other adults, family support for physical activity, and availability of playmates). The second included parent perception of environmental factors as barriers related to physical activity (size/layout of yard, size/layout of indoor space, neighborhood safety, and access to neighborhood play spaces). Child's age and gender were covariates controlled for in each analysis. Odds Ratios (OR) and 95\% Confidence Intervals (CI) were computed. A linear regression was run to test for multicollinearity, and a BoxTidwell test was conducted to test assumptions of linearity. Neither assumption was violated.

\section{RESULTS}

Descriptive statistics are presented in Table 1. The children represented in the sample were almost equal in terms of gender (51.4\% male), with a mean age of 8.1 years. Most (63.7\%) parents reported their child had decreased physical activity during stayat-home orders, while $36.3 \%$ indicated physical activity stayed the same or increased.

Availability of playmates was the most frequently reported social environment barrier to children's physical activity during stay-at-home orders (66\%). Over half (54.9\%) of parents reported their schedules were a barrier. Few parents (4.9\%) identified support for physical activity from other adults or family members as a barrier to children's physical activity. Most parents
TABLE 1 | Descriptive data for demographic characteristics, physical and social environmental barriers to children's physical activity during COVID-19 stay-at-home orders.

\begin{tabular}{|c|c|c|}
\hline & $N$ & $\%$ \\
\hline & 245 & 100 \\
\hline \multicolumn{3}{|l|}{ Child gender } \\
\hline Male & 126 & 51.4 \\
\hline Female & 119 & 48.6 \\
\hline Nonbinary/other & 0 & 0 \\
\hline Missing & 0 & \\
\hline \multicolumn{3}{|l|}{ Child age } \\
\hline 5 & 20 & 7.8 \\
\hline 6 & 29 & 11.8 \\
\hline 7 & 39 & 15.9 \\
\hline 8 & 58 & 23.7 \\
\hline 9 & 39 & 15.9 \\
\hline 10 & 38 & 15.5 \\
\hline 11 & 21 & 8.6 \\
\hline 12 & 2 & 0.8 \\
\hline Missing & 0 & \\
\hline \multicolumn{3}{|l|}{ Change in child physical activity } \\
\hline Increased & 49 & 20 \\
\hline Stayed same & 40 & 16.3 \\
\hline Decrease & 156 & 63.7 \\
\hline \multicolumn{3}{|l|}{ Social barriers $^{a}$} \\
\hline Availability of playmates & 161 & 66.0 \\
\hline Parent schedule & 134 & 54.9 \\
\hline Availability of adult supervision & 70 & 28.7 \\
\hline Parent interest in physical activity & 66 & 27.0 \\
\hline Availability of other adults & 12 & 4.9 \\
\hline Family support for physical activity & 12 & 4.9 \\
\hline Missing & 0 & \\
\hline \multicolumn{3}{|l|}{ Number of social barriers reported } \\
\hline 0 & 72 & 29.5 \\
\hline $1-2$ & 140 & 57.2 \\
\hline $3-4$ & 32 & 13.2 \\
\hline $5-6$ & 1 & 0.04 \\
\hline Missing & 0 & \\
\hline \multicolumn{3}{|l|}{ Environmental barriers ${ }^{a}$} \\
\hline Access to neighborhood play spaces & 102 & 41.8 \\
\hline Size/layout of indoor spaces & 55 & 22.5 \\
\hline Size/layout of yard & 37 & 15.2 \\
\hline Neighborhood safety & 16 & 6.6 \\
\hline Missing & 0 & \\
\hline \multicolumn{3}{|c|}{ Number of environmental barriers reported } \\
\hline None & 125 & 51.0 \\
\hline $1-2$ & 93 & 37.9 \\
\hline $3-4$ & 27 & 11.1 \\
\hline Missing & 0 & \\
\hline \multicolumn{3}{|c|}{ How often barriers impact physical activity } \\
\hline Rarely/never & 57 & 23.4 \\
\hline Sometimes & 130 & 53.2 \\
\hline Often/always & 57 & 23.4 \\
\hline Missing & 1 & \\
\hline
\end{tabular}

aNumber and percent reflect a "yes" response to perception of the factor as a barrier to child physical activity. 
(70\%) reported at least one social environment barrier, with $13 \%$ reporting three or more. The most commonly identified environmental factor as a barrier for physical activity during stay-at-home was access to neighborhood play places (40\%). The size and layout of indoor space (22\%) and yard (15\%) were less frequently reported environmental barriers. Neighborhood safety was indicated as a barrier to children's physical activity by $6.6 \%$ of parents. Almost half (49\%) of parents reported at least one environmental factor as a barrier to their child's physical activity.

Statistically significant correlations were found between change in child's physical activity and frequency of barriers, availability of adult supervision, parent schedule, availability of playmates, size/layout of indoor space, size or lack of yard, and lack of neighborhood play space. Games-Howell post-hoc tests found statistically significant between-group differences between parents reporting no social barriers and those reporting two or more. There was also a statistically significant between-group difference between parents reporting no environmental barriers and those with two or more environmental barriers.

A multivariate logistic regression explored the association between change in physical activity and social barriers. Several factors emerged as significant for a decrease in child physical activity compared with no change in child physical activity (see Table 2). Perception of availability of playmates as a barrier was associated with decreased children's physical activity during COVID-19 stay-at-home orders (OR $=4.72$; 95\% CI: $2.00-$ 11.17). Reporting that availability of adult supervision was a barrier for physical activity was associated with greater likelihood of reporting a decrease in children's physical activity $(\mathrm{OR}=11.82$; 95\% CI: 2.48-56.28). Participants reporting their children had experienced social barriers to physical activity often or always was associated with decreased physical activity more than those reporting barriers less often (OR $=10.73$; 95\% CI: 1.88-61.23). In the analysis of factors associated with increased physical activity during stay-at-home orders, only one factor emerged as significant. Reporting that adult supervision was not a barrier to children's physical activity was associated with an increase in their children's physical activity (OR $=9.89$; 95\%CI: $1.90-51.61)$.

In a multivariate logistic regression analysis of change in child physical activity and environmental factors as barriers, none were significantly associated with decrease in physical activity vs. no change in physical activity (size/layout of indoor spaces, size/presence of yard, neighborhood safety, access to neighborhood play spaces). However, higher frequency (always or often) of reported environmental factors as barriers significantly increased the odds of decreased child physical activity (see Table 3). None of the environmental factors as barriers emerged as significant when comparing increase in child physical activity and no change in physical activity.

\section{DISCUSSION}

The quick progression of the COVID-19 pandemic resulted in many states, counties, and municipalities recommending or requiring stay-at-home orders from March through May 2020. While the stay-at-home orders are recognized as an effective
TABLE 2 | Logistic regression associations of social and environmental barriers with decreased child physical activity during COVID-19 stay-at-home orders.

\begin{tabular}{|c|c|c|c|}
\hline & Odds ratio & $\begin{array}{l}95 \% \text { Confidence } \\
\text { intervals }\end{array}$ & $p$-value \\
\hline \multicolumn{4}{|c|}{ Decrease in physical activity vs. no change $(N=245)$} \\
\hline \multicolumn{4}{|l|}{ Demographics } \\
\hline Child age & 1.305 & $1.02,1.68$ & $0.04^{*}$ \\
\hline \multicolumn{4}{|l|}{ Child gender } \\
\hline Female & - & - & \\
\hline Male & 0.63 & $0.28,1.41$ & 0.26 \\
\hline \multicolumn{4}{|l|}{ Social barriers ${ }^{\mathrm{a}}$} \\
\hline Availability of playmates & 4.72 & $2.00,11.17$ & $0.00^{*}$ \\
\hline Parent schedule & 1.57 & $0.66,3.70$ & 0.30 \\
\hline $\begin{array}{l}\text { Availability of adult } \\
\text { supervision }\end{array}$ & 11.82 & $2.48,56.28$ & $0.00^{\star}$ \\
\hline $\begin{array}{l}\text { Parent interest in } \\
\text { physical activity }\end{array}$ & 0.64 & $0.25,1.66$ & 0.36 \\
\hline $\begin{array}{l}\text { Availability of other } \\
\text { adults }\end{array}$ & 0.38 & $0.06,2.32$ & 0.29 \\
\hline Family support for & 1.05 & $0.07,15.75$ & 0.97 \\
\hline
\end{tabular}

physical activity

\section{Frequency of barriers to physical activity ${ }^{b}$}

Rarely/never

Sometimes

Always/often

\subsection{6}

$0.66,4.76$

0.26

Decrease in physical activity vs. no change $(N=245)$

\section{Demographics}

Child age

1.19

$0.95,1.49$

0.13

Child gender

Female

Male

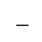

0.75

$0.35,1.63$

0.47

Environmental barriers ${ }^{a}$

Access to

1.77

$0.72,4.35$

0.22

neighborhood play

spaces

Size/layout of indoor

spaces

Size/layout of yard

1.50

$0.48,4.70$

0.49

Neighborhood safety

5.75

$0.66,50.28$

0.11

Frequency of barriers to physical activity ${ }^{b}$

Rarely/never

Sometimes

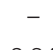

Always/often

\subsection{4}

$0.97,5.68$

$0.00^{*}$

aparticipants reported a "yes" response to perception of the factor as a barrier to child physical activity.

${ }^{b}$ Responses to the question "During stay-at-home, how often do factors keep your child from being regularly physically active?".

strategy to prevent spread of the virus (26), it created a massive shift in work, school, and family life. The majority of parents in the current study reported a perceived decrease in physical activity of their children during this time. These results are similar to the results in the Dunton study comparing parental perception of child physical activity pre-COVID-19 pandemic (February 2020) to early COVID-19 pandemic (April through 
TABLE 3 | Logistic regression associations of environmental barriers with increased child physical activity during COVID-19 stay-at-home orders.

\begin{tabular}{|c|c|c|c|}
\hline & Odds ratio & $\begin{array}{l}95 \% \text { Confidence } \\
\text { intervals }\end{array}$ & $p$-value \\
\hline \multicolumn{4}{|c|}{ Increase in physical activity vs. no change $(N=245)$} \\
\hline \multicolumn{4}{|l|}{ Demographics } \\
\hline Child age & 0.98 & $0.74,1.29$ & 0.87 \\
\hline \multicolumn{4}{|l|}{ Child gender } \\
\hline Female & - & - & \\
\hline Male & 0.52 & $0.21,1.26$ & 0.15 \\
\hline \multicolumn{4}{|l|}{ Social barriers ${ }^{a}$} \\
\hline Availability of playmates & 1.75 & $0.68,4.50$ & 0.25 \\
\hline Parent schedule & 0.59 & $0.22,1.60$ & 0.30 \\
\hline $\begin{array}{l}\text { Availability of adult } \\
\text { supervision }\end{array}$ & 9.89 & $1.90,51.61$ & $0.01^{*}$ \\
\hline $\begin{array}{l}\text { Parent interest in } \\
\text { physical activity }\end{array}$ & 0.44 & $0.14,1.36$ & 0.15 \\
\hline $\begin{array}{l}\text { Availability of other } \\
\text { adults }\end{array}$ & 0.61 & $0.06,5.63$ & 0.66 \\
\hline $\begin{array}{l}\text { Family support for } \\
\text { physical activity }\end{array}$ & 4.69 & $0.33,65.89$ & 0.25 \\
\hline \multicolumn{4}{|c|}{ Frequency of barriers to physical activity ${ }^{b}$} \\
\hline Rarely/never & - & - & \\
\hline Sometimes & 0.47 & $0.17,1.33$ & 0.16 \\
\hline Always/often & 0.68 & $0.08,5.59$ & 0.72 \\
\hline \multicolumn{4}{|c|}{ Increase in physical activity vs. no change $(N=245)$} \\
\hline \multicolumn{4}{|l|}{ Demographics } \\
\hline Child age & 0.95 & $0.74,1.22$ & 0.68 \\
\hline \multicolumn{4}{|l|}{ Child gender } \\
\hline Female & - & - & \\
\hline Male & 0.62 & $0.26,1.46$ & 0.27 \\
\hline \multicolumn{4}{|l|}{ Environmental barriers $^{a}$} \\
\hline $\begin{array}{l}\text { Access to } \\
\text { neighborhood play } \\
\text { spaces }\end{array}$ & 1.77 & $0.72,4.35$ & 0.22 \\
\hline $\begin{array}{l}\text { Size/layout of indoor } \\
\text { spaces }\end{array}$ & 1.50 & $0.48,4.70$ & 0.49 \\
\hline Size/layout of yard & 5.75 & $0.66,50.28$ & 0.11 \\
\hline Neighborhood safety & 0.90 & $0.83,9.74$ & 0.93 \\
\hline \multicolumn{4}{|c|}{ Frequency of barriers to physical activity ${ }^{b}$} \\
\hline Rarely/never & - & - & \\
\hline Sometimes & 0.57 & $0.23,1.44$ & 0.24 \\
\hline Always/often & 0.90 & $0.13,6.19$ & 0.91 \\
\hline
\end{tabular}

a participants reported a "yes" response to perception of the factor as a barrier to child physical activity.

${ }^{b}$ Responses to the question "During stay-at-home, how often do factors keep your child from being regularly physically active?".

May 2020) (24). The decrease in physical activity, even if temporary, can negatively impact children's health as there is evidence to support many physical and mental health benefits of this behavior (26). Additionally, emerging research related to COVID-19 shows the protective effects of this behavior on mental health, depression, and anxiety (27-29).
This study aimed to explore physical and social environmental barriers to children's physical activity during stay-at-home orders. The most prevalent social barriers related to perceived decrease in children's physical activity were parent's schedule and lack of access to playmates. These findings concur with past research. In a systematic review of qualitative studies on barriers and facilitators to young children's physical activity, parents' busy schedule was a commonly reported barrier (30). Mailey et al. (31) also found scheduling constraints and work schedules to be barriers. These findings occurred pre-pandemic, and COVID19 is likely placing additional strains and disruptions in worklife balance. Parents have the extra task of navigating their children's virtual learning along with their own work-at-home responsibilities (23).

Parental support is positively associated with child physical activity $(26,32)$. However, increased family burden due to the pandemic will likely continue as a barrier to physical activity for children. There is a need for innovative resources for parents on ways to better support their child's physical activity as the pandemic continues. Building on The Community Guide's evidence-based recommendations for family physical activity interventions (33) is a potential starting point.

Lack of access to playmates was significantly associated with a decrease in physical activity in this study, which is consistent with evidence on the positive association of engagement with others in activity and overall physical activity for children (34-36). In a systematic review on the topic, peer-to-peer participation in physical activity resulted in greater amounts of children's physical activity in six of the seven studies reviewed (37). Edwards et al. (38) reported that parents considered friends and siblings to be strong influences on their children's structured and informal physical activity. The isolating effects of stay-athome orders impacted interactions among children. Children and adolescents virtually connected with friends during times of stay-at-home and physical distancing requirements (39). Although this mode of communication may still provide social connection, the lack of in-person interaction may also contribute to less active play together. Additionally, increased virtual communication may also increase the amount of their overall screen time and sedentary behavior, compounding subsequent negative health effects $(24,40,41)$. Promoting a combination of virtual connections with ways to engage in physical activity together is a potential intervention strategy.

In addition to the social environment, the physical environment has a significant influence on physical activity. Creating and improving places for physical activity is recommended as an evidence-based strategy to increase physical activity and improve fitness (33). Having safe and accessible places to play and be active are strong correlates for child physical activity $(30,32)$. Stay-at-home orders eliminated opportunities in the social environment for children to be physically active, such as physical education, recess, and participation in sports programs. Additionally, recreation centers, parks, and playgrounds were closed, restricting physical environment opportunities for physical activity. We assessed the environmental factors associated with physical activity including size and layout of indoor spaces and yard, perception 
of neighborhood safety, and access to neighborhood places to play. The most prevalent factor reported as a barrier to child physical activity was access to neighborhood play spaces, which is not surprising given the restrictions of the stay-at-home orders. None of the individual environmental factors studied emerged as significant predictors of change in child physical activity in multi-variate analysis. However, the aggregated total of perceived barriers was a significant influence on decreased physical activity. The lack of significance of individual environmental factors is contrary to past research on the importance of home environment (30,33,42), yard space (43), and community resources (44) to overall child physical activity. We hypothesize our conflicting findings may be due to several elements. First, the unique impact of stay-at-home orders may have modified the perception of environment as a barrier to physical activity. Second, we did not assess specific location of participants. In doing so we may have found a skewed sample living in environments which are highly supportive for physical activity. There are substantial inequities in home, neighborhood, and community supports for physical activity across and within geographic areas (45-47). A study with a larger sample and more geographic indicators would provide broader insight into how the presence or absence of community supports impact children's physical activity.

This exploratory study provided information about child physical activity during the early phases of the pandemic. This unprecedented time period provided a unique situation for this behavior not captured previously in research. In spite of its novelty, there are several limitations which warrant mention. First, this was a cross-sectional study and causality cannot be inferred. Second, selection bias due to convenience sampling may decrease internal validity. People who would likely visit the social media sites used in recruitment may share certain characteristics compared to those who are less active on social media. Third, incomplete responses also hindered analyses. The omission of many surveys with missing data, which if completed, may have changed our results, e.g., the inability to add parent characteristics such as socio-economic status and race/ethnicity to the models due to missing data. We were unable to discern whether participants were from states without stay-at-home orders if they did not provide demographic data. Offering an incentive is a potential strategy for improving completion of

\section{REFERENCES}

1. US Health and Human Services. 2008 Physical Activity Guidelines for Americans (2008). Available online at: www.health.gov/paguidelines (accessed August 28, 2020).

2. US Health and Human Services. Physical Activity Guidelines for Americans, 2nd edn (2018). Available online at: https://health.gov/sites/default/files/ 2019-09/Physical_Activity_Guidelines_2nd_edition.pdf (accessed August 28, 2020).

3. Trost SG, Owen N, Bauman AE, Sallis JF, Brown W. Correlates of adult participation in physical activity: review and update. Med Sci Sport Exerc. (2002) 34:1996-2001. doi: 10.1097/00005768-200212000-00020

4. Miller SM, Siegel JT. Youth sports and physical activity: the relationship between perceptions of childhood sport experience surveys in future studies. Lastly, there is a chance that the drastically changed circumstances of families spending so much time together at home impacted parents' perceptions. Despite these limitations, lessons learned from methods and analyses can inform future studies.

The unique aspects of the COVID-19 pandemic provide a natural experiment for exploring the impact of the physical and social environment on children's physical activity. Assessing current perceptions of physical activity and screen time provides information for planning future studies to track sustainability of both positive and negative behavior changes over time.

\section{DATA AVAILABILITY STATEMENT}

The data generated from this study is available from the authors by request.

\section{ETHICS STATEMENT}

The studies involving human participants were reviewed and approved by Washington University in Saint Louis Institutional Review Board.

\section{AUTHOR CONTRIBUTIONS}

AE: manuscript conception, design, and drafting manuscript. LS and AG: interpretation of relevant literature and data analysis. $\mathrm{AB}, \mathrm{SM}$, and $\mathrm{MK}$ : critical expertise and review. All authors contributed to the article and approved submitted version.

\section{FUNDING}

This study was funded by the Centers for Disease Control and Prevention U48DP006395, Prevention Research Centers Program.

\section{SUPPLEMENTARY MATERIAL}

The Supplementary Material for this article can be found online at: https://www.frontiersin.org/articles/10.3389/fpubh. 2021.637151/full\#supplementary-material

and adult exercise behavior. Psychol Sport Exerc. (2017) 33:85-92. doi: 10.1016/j.psychsport.2017.08.009

5. Fuemmeler BF, Pendzich MK, Tercyak KP. Weight, dietary behavior, and physical activity in childhood and adolescence: implications for adult cancer risk. Obes Facts. (2009) 2:179-86. doi: 10.1159/0002 20605

6. Fulton J. The State of Physical Activity in America. Atlanta, GA (2016). Available online at: https://health.gov/sites/default/files/2019-11/The-Stateof-Physical-Activity-in-America.pdf

7. Whitt-Glover MC, Taylor WC, Floyd MF, Yore MM, Yancey AK, Matthews CE. Disparities in physical activity and sedentary behaviors among US children and adolescents: prevalence, correlates, and intervention implications. J Public Health Policy. (2009) 30:S309-S34. doi: 10.1057/jphp.2 008.46 
8. Gortmaker SL, Lee R, Cradock AL, Sobol AM, Duncan DT, Wang YC. Disparities in youth physical activity in the United States: 2003-2006. Med Sci Sports Exerc. (2012) 44:888-93. doi: 10.1249/MSS.0b013e31823fb254

9. Beets MW, Bornstein D, Beighle A, Cardinal BJ, Morgan CF. Pedometermeasured physical activity patterns of youth. A 13-Country Review. Am J Prev Med. (2010) 38:208-16. doi: 10.1016/j.amepre.2009.09.045

10. Trost SG, Pate RR, Sallis JF, Freedson PS, Taylor WC, Dowda M, et al. Age and gender differences in objectively measured physical activity in youth. Med Sci Sports Exerc. (2002) 34:350-5. doi: 10.1097/00005768-200202000-00025

11. Physical Activity Guidelines Advisory Committee. 2018 Physical Activity Guidelines Advisory Committee Scientific Report (2018). Available online at: https://health.gov/paguidelines/second-edition/report/pdf/PAG_Advisory_ Committee_Report.pdf (accessed August 29, 2018).

12. Moreland A, Herlihy C, Tynan MA, Sunshine G, McCord RF, Hilton C, et al. Timing of state and territorial COVID-19 stay-at-home orders and changes in population movement - United States, March 1-May 31, 2020. MMWR Morb Mortal Wkly Rep. (2020) 69:1198-203. doi: 10.15585/mmwr.mm6935a2

13. Institute of Medicine. Educating the Student Body. Washington, DC: National Academies Press (2013).

14. Centers for Disease Control and Prevention. Guidance for Administrators in Parks and Recreational Facilities. Available online at: https://www.cdc. gov/coronavirus/2019-ncov/community/parks-rec/park-administrators.html (accessed September 17, 2020).

15. Bowler DE, Buyung-Ali LM, Knight TM, Pullin AS. A systematic review of evidence for the added benefits to health of exposure to natural environments. BMC Public Health. (2010) 10:456. doi: 10.1186/1471-2458-10-456

16. Lawton E, Brymer E, Clough P, Denovan A. The relationship between the physical activity environment, nature relatedness, anxiety, and the psychological well-being benefits of regular exercisers. Front Psychol. (2017) 8:1058. doi: 10.3389/fpsyg.2017.01058

17. Brymer E, Davids K, Mallabon L. Understanding the psychological health and well-being benefits of physical activity in nature: an ecological dynamics analysis. Ecopsychology. (2014) 6:189-97. doi: 10.1089/eco.2013.0110

18. Colley RC, Bushnik T, Langlois $K$. Exercise and screen time during the COVID-19 pandemic. Heal Reports. (2020) 31:1-11. doi: 10.25318/82-003-x202000600001-eng

19. Qin F, Song Y, Nassis GP, Zhao L, Dong Y, Zhao C, et al. Physical activity, screen time, and emotional well-being during the 2019 novel coronavirus outbreak in China. Int J Environ Res Public Health. (2020) 17:5170. doi: 10.3390/ijerph17145170

20. Jurak G, Morrison SA, Leskošek B, Kovač M, HadŽić V, Vodičar J, et al. Physical activity recommendations during the coronavirus disease-2019 virus outbreak. J Sport Heal Sci. (2020) 9:325-7. doi: 10.1016/j.jshs.2020.05.003

21. Pietrobelli A, Pecoraro L, Ferruzzi A, Heo M, Faith M, Zoller T, et al. Effects of COVID-19 lockdown on lifestyle behaviors in children with obesity living in Verona, Italy: a longitudinal study. Obesity. (2020) 28:1382-5. doi: 10.1002/oby.22861

22. Fontanesi L, Marchetti D, Mazza C, Di Giandomenico S, Roma P, Verrocchio MC. The effect of the COVID-19 lockdown on parents: a call to adopt urgent measures. Psychol Trauma Theory Res Pract Policy. (2020) 12:S79-S81. doi: $10.1037 /$ tra0000672

23. Craig L, Churchill B. Dual-earner parent couples' work and care during COVID-19. Gender Work Organ. (2020) 28:66-79. doi: 10.1111/gwao.12497

24. Dunton GF, Do B, Wang SD. Early effects of the COVID-19 pandemic on physical activity and sedentary behavior in children living in the U.S. BMC Public Health. (2020) 20:1351. doi: 10.1186/s12889-020-09429-3

25. Vaughn AE, Hales DP, Neshteruk CD, Ward DS. HomeSTEAD's physical activity and screen media practices and beliefs survey: instrument development and integrated conceptual model. PLoS One. (2019) 14:e0226984 doi: 10.1371/journal.pone.02 26984

26. Physical Activity Guidelines Advisory Committee. 2018 Physical Activity Guidelines Advisory Committee Scientific Report. Washington, DC (2018). Available online at: https://health.gov/paguidelines/second-edition/report/ pdf/PAG_Advisory_Committee_Report.pdf (accessed January 22, 2019).

27. Schuch FB, Bulzing RA, Meyer J, Vancampfort D, Firth J, Stubbs B, et al. Associations of moderate to vigorous physical activity and sedentary behavior with depressive and anxiety symptoms in self-isolating people during the
COVID-19 pandemic: a cross-sectional survey in Brazil. Psychiatry Res. (2020) 292:113339. doi: 10.1016/j.psychres.2020.113339

28. Eyler A, Schmidt L, Gilbert A, Beck A, Kepper M, Mazzucca S. Children's physical activity and screen time during COVID-19 pandemic: a qualitative exploration of parental perceptions. Health Behav Policy Rev. (In press).

29. Gilbert A, Eyler A, Schmidt L, Beck A, Kepper A, Mazzucca S. Associations of physical activity and sedentary behaviors with child mental well-being during the COVID-19 pandemic. In: Institute for Public Health 13th Annual Conference (2020). Available online at: https://publichealth.wustl.edu/events/ institute-for-public-health-13th-annual-conference-poster-session/

30. Hesketh KR, Lakshman R, van Sluijs EMF. Barriers and facilitators to young children's physical activity and sedentary behaviour: a systematic review and synthesis of qualitative literature. Obes Rev. (2017) 18:987-017. doi: 10.1111/obr.12562

31. Mailey EL, Huberty J, Dinkel D, McAuley E. Physical activity barriers and facilitators among working mothers and fathers. BMC Public Health. (2014) 14:657. doi: 10.1186/1471-2458-14-657

32. Trost SG, Loprinzi PD. Parental influences on physical activity behavior in children and adolescents: a brief review. Am J Lifestyle Med. (2011) 5:171-81. doi: 10.1177/1559827610387236

33. Physical Activity: Family-Based Interventions | The Community Guide. Available online at: https://www.thecommunityguide.org/findings/physicalactivity-family-based-interventions (accessed October 28, 2020).

34. Jago R, MacDonald-Wallis K, Thompson JL, Page AS, Brockman R, Fox KR. Better with a Buddy. Med Sci Sport Exerc. (2011) 43:259-65. doi: 10.1249/MSS.0b013e3181edefaa

35. Xu S, Wang Y, Jing Y, Wang Z, Wang J. Influence of parents' physical activity on children's physical activity and cardiopulmonary endurance. Med Sci Sport Exerc. (2019) 51:514. doi: 10.1249/01.mss.0000562046.04457.8f

36. Sawka KJ, McCormack GR, Nettel-Aguirre A, Hawe P, Doyle-Baker PK. Friendship networks and physical activity and sedentary behavior among youth: a systematized review. Int J Behav Nutr Phys Act. (2013) 10:130. doi: 10.1186/1479-5868-10-130

37. Maturo CC, Cunningham SA. Influence of friends on children's physical activity: a review. Am J Public Health. (2013) 103:e23-38. doi: 10.2105/AJPH.2013.301366

38. Edwards MJ, Jago R, Sebire SJ, Kesten JM, Pool L, Thompson JL. The influence of friends and siblings on the physical activity and screen viewing behaviours of children aged 5-6 years: a qualitative analysis of parent interviews. BMJ Open. (2015) 5:e006593. doi: 10.1136/bmjopen-2014-006593

39. Ellis WE, Dumas TM, Forbes LM. Physically isolated but socially connected: psychological adjustment and stress among adolescents during the initial COVID-19 crisis. Can J Behav Sci. (2020) 52:177-87. doi: 10.1037/cbs0000215

40. Thomas G, Bennie JA, De Cocker K, Castro O, Biddle SJH. A descriptive epidemiology of screen-based devices by children and adolescents: a scoping review of 130 surveillance studies since 2000. Child Indic Res. (2020) 13:93550. doi: 10.1007/s12187-019-09663-1

41. Sandercock G RH, Ogunleye A, Voss C. Screen time and physical activity in youth: thief of time or lifestyle choice? J Phys Act Health. (2012) 9:977-84. doi: 10.1123/jpah.9.7.977

42. Attridge M, Creamer J, Ramsden M, Cannings-John R, Hawthorne K. Culturally appropriate health education for people in ethnic minority groups with type 2 diabetes mellitus. Cochrane Database Syst Rev. (2014) 9:CD006424. doi: 10.1002/14651858.CD006424.pub3

43. Sheldrick MP, Maitland C, Mackintosh KA, Rosenberg M, Griffiths LJ, Fry R, et al. Associations between the home physical environment and children's home-based physical activity and sitting. Int J Environ Res Public Health. (2019) 16:4178. doi: 10.3390/ijerph162 14178

44. Community Preventive Services Taskforce. Physical Activity: Increased Access to Places | The Community Guide (2020). Available online at: https://www.thecommunityguide.org/findings/physical-activity-creatingor-improving-places-physical-activity (accessed October 28, 2020).

45. Carroll-Scott A, Gilstad-Hayden K, Rosenthal L, Eldahan A, McCaslin C, Peters SM, et al. Associations of neighborhood and school socioeconomic and social contexts with body mass index among urban preadolescent students. Am J Public Health. (2015) 105:2496-502. doi: 10.2105/AJPH.2015.3 02882 
46. Carroll-Scott A, Gilstad-Hayden K, Rosenthal L, Peters SM, McCaslin C, Joyce R, et al. Disentangling neighborhood contextual associations with child body mass index, diet, and physical activity: The role of built, socioeconomic, and social environments. Soc Sci Med. (2013) 95:106-14. doi: 10.1016/j.socscimed.2013. 04.003

47. Jia $\mathrm{P}$, Xue $\mathrm{H}$, Cheng $\mathrm{X}$, Wang $\mathrm{Y}$. Effects of school neighborhood food environments on childhood obesity at multiple scales: a longitudinal kindergarten cohort study in the USA. BMC Med. (2019) 17:99. doi: 10.1186/s12916-019$1329-2$
Conflict of Interest: The authors declare that the research was conducted in the absence of any commercial or financial relationships that could be construed as a potential conflict of interest.

Copyright (C) 2021 Eyler, Schmidt, Kepper, Mazzucca, Gilbert and Beck. This is an open-access article distributed under the terms of the Creative Commons Attribution License (CC BY). The use, distribution or reproduction in other forums is permitted, provided the original author(s) and the copyright owner(s) are credited and that the original publication in this journal is cited, in accordance with accepted academic practice. No use, distribution or reproduction is permitted which does not comply with these terms. 